\title{
A new ocean mean dynamic topography model, derived from a combination of gravity, altimetry and drifter velocity data
}

\author{
Knudsen, Per; Andersen, Ole; Maximenko, Nikolai
}

Published in:

Advances in Space Research

Link to article, DOI:

10.1016/j.asr.2019.12.001

Publication date:

2021

Document Version

Peer reviewed version

Link back to DTU Orbit

Citation (APA):

Knudsen, P., Andersen, O., \& Maximenko, N. (2021). A new ocean mean dynamic topography model, derived from a combination of gravity, altimetry and drifter velocity data. Advances in Space Research, 68(2), 10901102. https://doi.org/10.1016/j.asr.2019.12.001

\section{General rights}

Copyright and moral rights for the publications made accessible in the public portal are retained by the authors and/or other copyright owners and it is a condition of accessing publications that users recognise and abide by the legal requirements associated with these rights.

- Users may download and print one copy of any publication from the public portal for the purpose of private study or research.

- You may not further distribute the material or use it for any profit-making activity or commercial gain

- You may freely distribute the URL identifying the publication in the public portal 


\section{Journal Pre-proofs}

A new ocean mean dynamic topography model, derived from a combination of gravity, altimetry and drifter velocity data

Per Knudsen, Ole Andersen, Nikolai Maximenko

PII:

S0273-1177(19)30849-X

DOI: https://doi.org/10.1016/j.asr.2019.12.001

Reference:

JASR 14565

To appear in:

Advances in Space Research

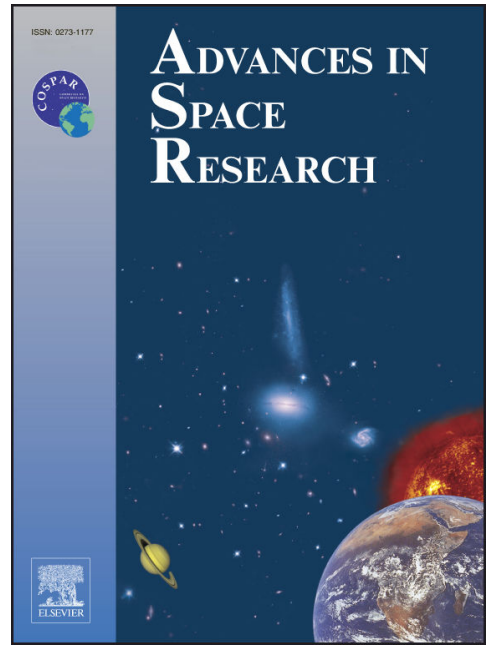

Received Date: $\quad 3$ June 2019

Revised Date: $\quad 28$ November 2019

Accepted Date: $\quad 1$ December 2019

Please cite this article as: Knudsen, P., Andersen, O., Maximenko, N., A new ocean mean dynamic topography model, derived from a combination of gravity, altimetry and drifter velocity data, Advances in Space Research (2019), doi: https://doi.org/10.1016/j.asr.2019.12.001

This is a PDF file of an article that has undergone enhancements after acceptance, such as the addition of a cover page and metadata, and formatting for readability, but it is not yet the definitive version of record. This version will undergo additional copyediting, typesetting and review before it is published in its final form, but we are providing this version to give early visibility of the article. Please note that, during the production process, errors may be discovered which could affect the content, and all legal disclaimers that apply to the journal pertain.

(C) 2019 Published by Elsevier Ltd on behalf of COSPAR. 


\title{
A new ocean mean dynamic topography model, derived from a combination of gravity, altimetry and drifter velocity data.
}

By

Per Knudsen,

Technical University of Denmark, DTU Space, Elektrovej 327, 2800 Kongens Lyngby, Denmark.

Ole Andersen,

Technical University of Denmark, DTU Space, Elektrovej 327, 2800 Kongens Lyngby, Denmark.

Nikolai Maximenko

University of Hawaii at Manoa, IPRC, 1680 East-West Road, Honolulu, Hawai’i 96822, USA

\begin{abstract}
.
We present a new mean dynamic ocean topography product based on the improved geoid model, derived in the Optimal Geoid for Modelling Ocean Circulation (OGMOC) project supported by the European Space Agency. This geoid model is based on the Gravity Recovery and Climate Experiment (GRACE) and the Gravity Field and Steady-State Ocean Circulation Explorer (GOCE) satellite missions combined with the newer DTU15GRA altimetric surface gravity and it was optimized to eliminate artificial features common for other geoid models such as striations and orange skin. Subsequently, the model has been augmented using the EIGEN-6C4 coefficients to harmonic degree 2160. The new geodetic mean dynamic ocean topography model DTU17MDT has been derived using this geoid model and the DTU15MSS mean sea surface, with the quasigaussian filter optimized to best fit velocities of oceanographic drifting buoys. The new model improves the resolution of important details of the ocean circulation. Finally, the drifter data were integrated into the model to refine its spatial resolution. The new topography product DTU17cMDT, combining the wealth of information from satellite gravity and altimetry and drifters, is rich with more features of the ocean surface circulation. In particular, as shown in the case of the Gulf Stream off the east coast of Florida, DTU17cMDT improves description of the western boundary currents.
\end{abstract}

\section{Background}

The Gravity Recovery and Climate Experiment (GRACE) and in particular the Gravity Field and Steady-State Ocean Circulation Explorer (GOCE) satellite missions have improved the computation of the mean dynamic topography (MDT) of the ocean significantly, so that even fine scale structures in the ocean general circulation were recovered (Bingham et al., 2010, Knudsen et al., 2014). Although the results were very convincing, there were issues remaining in construction of the optimal geoid model and in the combination with the altimetric mean sea surface (MSS) to determine the MDT. Results from analyses assessing the GOCE gravity models using MSS and drifter velocities (e.g. Knudsen et al., 2015) clearly confirmed that GOCE and the increasing number of data through its lifetime has improved the modelling of the gravity field, resulting in more accurate products of MDT and geostrophic ocean surface currents. However, the analyses also identified some common errors in the gravity models, computed from the combination of GRACE 
and GOCE data. In terms of spherical harmonics those errors are associated with harmonic d/o 100120 showing distinctive artificial striated patterns, contaminating the estimates of the north-south component of the ocean currents. Additional issues related to orange-skin features (after the texture of an orange) in some models associated with harmonic $\mathrm{d} / \mathrm{o} 150-250$ had been identified.

Within the ESA supported Optimal Geoid for Modelling Ocean Circulation (OGMOC) project, a targeted activity was initiated to bring key expertise together to study the nature of those characteristic errors further and to derive an optimal geoid model suitable for estimation of highquality MDT. It was based on the GOCO05C framework (described in Fecher et al., 2017), used in combination with the newer DTU15GRA altimetric surface gravity (Andersen et al., 2017). Subsequently, the model has been augmented using the EIGEN-6C4 coefficients (Förste et al., 2011) to $\mathrm{d} / \mathrm{o} 2160$. Compared to other geoid models, the OGMOC geoid model had been optimized to avoid striations and bubble-like features.

In addition to the satellite-based information, and prior to the launch of both GRACE and GOCE, drifter data has been acquired from national and international programmes (Niiler, 2001; Niiler, 2003; Maximenko et al., 2013) such as the World Ocean Experiment Surface Velocity Programme and Global Drifter Program (https://www.aoml.noaa.gov/phod/gdp/) launching buoys in the world oceans. This vast source of information has been extremely valuable in studies of the ocean circulation and recovered important details of the near surface currents. Drifter data has also been used to improve the estimation of the MDT (Niiler et al., 2003; Maximenko et al., 2009) and global MDT models have been derived by integrating altimetry, GRACE geoid models and drifters (Rio and Hernandez, 2004, Maximenko et al., 2009, and Rio et al., 2011). Prior to this study the recent geoid models based on GOCE have not yet been included in such computations.

In this paper we derive an optimal geodetic MDT, using the new geoid model, and compare it with oceanographic data. Finally, the geodetic MDT is merged with oceanographic information to form a state-of-the-art MDT and ocean surface mean circulation model.

\section{Methodology}

The practical task of computing a geodetic mean dynamic topography (MDT) from a mean sea surface (MSS) and a geoid is conceptually very simple; however, there are important issues that must be considered in order to obtain a good MDT product (e.g. Haines et al., 2011). Both the MSS and the geoid must be represented relative to the same reference ellipsoid and in the same tidal system. Then the MDT is expressed by

$\eta=\bar{h}-N$

Where $\bar{h}$ is the height of the mean sea surface above the reference ellipsoid and $N$ is the geoid height relative to the same reference ellipsoid. Ocean surface exhibits many modes of variability, so that each MSS product is associated with a specific time period. When using the MDT together with sea level anomaly, derived from satellite altimetry, it is important that the altimetry used for the MSS in the MDT calculation has the same corrections applied as the altimetry that is used for the computation of the sea level anomalies. Also, it is important that the reference time periods match. 
Global gravity field models such as the GOCE models are normally represented in terms of spherical harmonic coefficient up to a certain harmonic degree and order $L$. As described in Knudsen et al. (2011), when subtracting such a geoid model based on such a set of coefficients from the MSS, then the residual heights may be described as follows.

$\Delta h=\bar{h}-N_{L}=\eta+N-N_{L}=\eta+\Delta N_{L}$

consist of the MDT plus those parts of the geoid that are not resolved by the geoid model, $\Delta N_{L}$. The unresolved parts of the geoid are mainly associated with harmonic degrees above $L$. Naturally errors in both the MSS and in the gravity field model will play a role, but they are ignored at this stage. Subsequently, a proper filtering of the differences is required to eliminate the unresolved parts of the geoid to obtain a useful estimate of the MDT. That is

$\hat{\eta}=F \circ\left(\eta+\Delta N_{L}\right)$

Where the MDT estimate is obtained by applying a filter $F$ on the height residuals in Eq. (2). The best estimate in a least squares sense

$\left\|\eta-F \circ\left(\eta+\Delta N_{L}\right)\right\|=\left\|\eta-F \circ \eta-F \circ \Delta N_{L}\right\| \leq\|\eta-F \circ \eta\|+\left\|F \circ \Delta N_{L}\right\|$

is obtained when the filtering does little harm to the MDT and minimizes the short scale geoid signals.

This filtering may be carried out in either the space domain, where the MSS is usually represented, or in the spectral domain where global geoid models are usually represented. Both methods have their advantages and their disadvantages. In both cases, it may be recommended to augment the GOCE spherical harmonic series using other higher degree harmonic expansions of the gravity field to reduce the magnitude of the short scale geoid signal in the MSS. The computation of the MDTs follows the recommendations from the GOCE User Toolbox (GUT) tutorials and was partly carried out using GUT tools (Benveniste et al., 2007).

Surface geostrophic currents are associated with the slope of the MDT. If accelerations and friction terms are neglected and horizontal pressure gradients in the atmosphere are absent, then the components of the surface geostrophic currents, the Eastward component $u$ and the Northward component $v$, are obtained from the slopes of the MDT by

$u=\frac{-g \partial \eta}{f R \partial \phi}, v=\frac{g \quad \partial \eta}{f R \cos \phi \partial \lambda}$

where $f=2 \omega_{e} \sin \phi$ is the Coriolis force coefficient, $\omega_{e}$ is the angular velocity of the Earth, $R$ is the mean radius of the Earth, $\phi$ is the latitude, $\lambda$ is the longitude, and $g$ is acceleration due to gravity. The Coriolis force coefficient is zero at the Equator. Lagerloef et al. (1999) describe how the geostrophic relation based on the second order derivatives of the MDT may be obtained at the Equator by applying the rule of L'Hopital. Subsequently, Bonjean and Lagerloef (2002) propose a strategy for implementing the methodology. However, during the computations a simplified handling of the Coriolis coefficient was applied in order to overcome problems due to non-zero slopes at the Equator caused by influence of non-geostrophic ocean signals and observation errors. 
In practice, the Coriolis coefficient was modified in the Equatorial band, so that $f=2 \omega_{e} \cdot 0.02$ for $0^{\circ} \leq \phi \leq 1^{\circ}$ and $f=-2 \omega_{e} \cdot 0.02$ for $-1^{\circ} \leq \phi \leq 0^{\circ}$ was applied.

An oceanographic MDT may be obtained from a set of mean geostrophic surface current observations using the following least squares inversion

$\eta=\left(A^{T} C_{e}^{-1} A\right)^{-1} A^{T}\left(\begin{array}{l}u \\ v\end{array}\right)$

Where the design matrix $A$ relates the observed velocity components, $u$ and $v$, with the MDT using Eq. (5). $C_{e}$ is the error covariance matrix associated with the observations. The estimation may be enhanced by using the geodetic MDT as a-priori information, hence, a combination MDT is obtained. The equations may be further augmented to include constraints to regularize the inversion and obtain a smoother solution less affected by errors in the data (Tikhonov, 1943).

\section{Computation of the Geodetic MDT}

The computation of the geodetic MDT is based on the combined OGMOC geoid model in which the marine gravity derived from satellite altimetry (Andersen et al., 2017) had been included to reduce the unresolved parts of the geoid up to harmonic degree and order $2160\left(\Delta N_{L}\right.$ in eq.2-4). Hence, less filtering is needed to reduce the effects of the shorter scale geoid signals that are not recovered by GRACE and GOCE. Although, the gravity derived from satellite altimetry is based on mean sea surface heights and not purely the gravimetric geoid, the less filtering is believed to improve the recovery of the ocean signal. As mean sea surface model, the DTU15MSS mean sea surface (an updated version of DTU13MSS described in Andersen et al., 2015). It has been computed using multi-mission altimeter data and represents a 20-years mean (1993-2012).

The filtering was carried out using a quasi-gaussian filter, i.e., a Gaussian function that is truncated at 2.5 times the standard deviation. To assess the impact of the filtering and to determine the optimal filter width, four models were derived using half-widths of $0.4^{\circ}, 0.6^{\circ}, 0.8^{\circ}$, and $1.0^{\circ}$ respectively. Subsequently, geostrophic surface currents were computed from each model using Eq. (5). Then the derived current components were compared with mean surface currents derived from ocean drifters (see the Appendix for details). Mean drifter velocities obtained in $1 / 4^{\circ}$ by $1 / 4^{\circ}$ cells in which at least 20 drifter velocities were found, were used. The drifter velocities were not filtered subsequently, because a best fit to the unfiltered currents is sought. The results of the comparisons are shown in Fig. 1. 


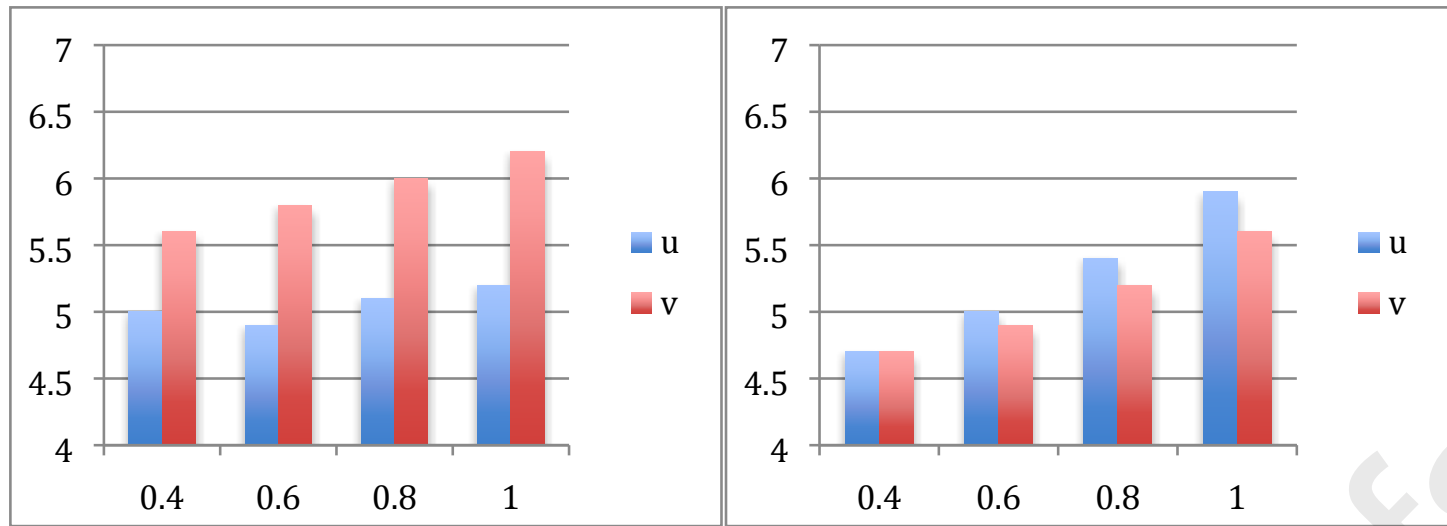

Figure 1: Bar charts showing the RMS values in $\mathrm{cm} / \mathrm{s}$ of the differences between geostrophic current, derived from MDT filtered using $0.4^{\circ}, 0.6^{\circ}, 0.8^{\circ}$, and $1.0^{\circ}$ half-width filters, respectively, and drifter currents at latitudes $10^{\circ}-30^{\circ}$ (left) and latitudes $30^{\circ}-50^{\circ}$ (right).

The results of the comparisons (Fig. 1) show that the largest RMS values are obtained when most details in the MDT have been removed by smoothing. The lowest RMS values are obtained by using a half-width of $0.4^{\circ}$. However, for the u-component at low latitudes $\left(10^{\circ}-30^{\circ}\right)$ the lowest RMS is obtained when using a half-width of $0.6^{\circ}$. The differences between the two MDT models obtained using $0.4^{\circ}$ and $0.6^{\circ}$ as half-widths for the filtering, respectively, may be assessed further by inspecting a plot of the differences (shown in Fig. 2). The plot displays differences of a few centimetres only. However, consistent signals are found in areas associated with the major ocean currents and more noisy patterns are found in the low-energy parts of the oceans. As we wish to maintain the details of the currents and get rid of the noisy parts, it was decided to blend the MDTs obtained using $0.4^{\circ}$ and $0.6^{\circ}$ as half-widths for the filtering. The blending of the two solutions was carried out by using a scalar field as weights when interpolating between them. The scalar field was constructed using the local standard deviations of the MDT heights within $1^{\circ}$ by $1^{\circ}$ cells, so that values close to zero are obtained in the quiet parts of the oceans and so that values approaching one are obtained in the dynamic parts. The scalar field is shown in Fig. 3. When interpolating between the two models the resulting model will reproduce the $0.6^{\circ}$ half-width model in the quiet parts and the $0.4^{\circ}$ half-width model in the dynamic parts of the oceans, hence, maintaining the consistent features and leaving out the noisier features viewed in Fig. 2.

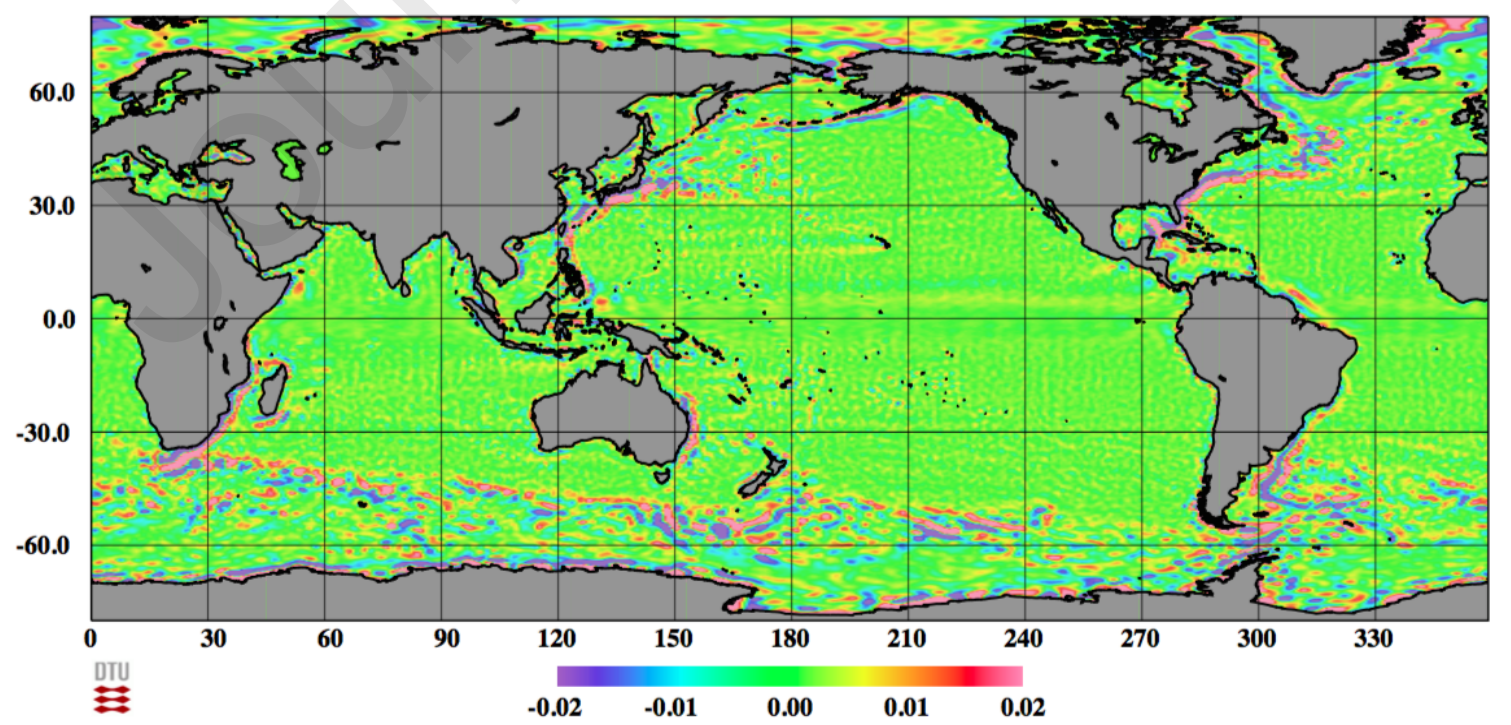


Figure 2: Difference between the MDT models obtained using $0.4^{\circ}$ and $0.6^{\circ}$ for the filtering. Units are meters.

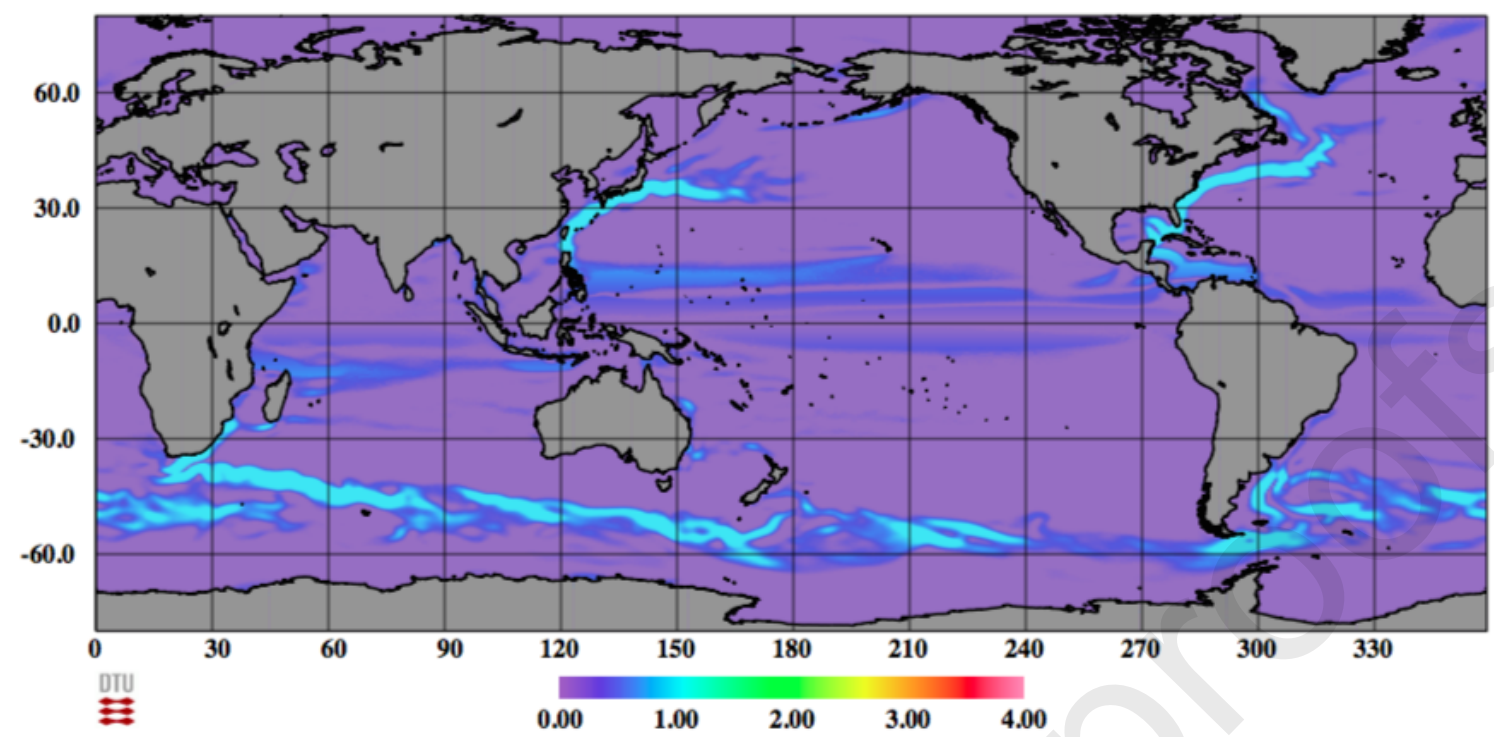

Figure 3: Scalar field to be applied for the interpolation between the two MDT models obtained using half-widths of $0.4^{\circ}$ and $0.6^{\circ}$ respectively.

The resulting geodetic mean dynamic topography model DTU17MDT is shown in Fig. 4. The model recovers well the well-known features associated with the major ocean currents, mainly the sub-tropical gyres and the Antarctic Circumpolar Current (ACC). Geostrophic surface mean current components were computed subsequently using eq. (5) (shown in Fig. 5). The currents display more details associated with the western boundary currents, the ACC, and the Equatorial currents in particular. A fit to the drifter $u$ and $v$ velocities within RMS values of the differences of $4.9 \mathrm{~cm} / \mathrm{s}$ and $5.5 \mathrm{~cm} / \mathrm{s}$ at latitudes $10^{\circ}-30^{\circ}$ and $4.7 \mathrm{~cm} / \mathrm{s}$ and $4.7 \mathrm{~cm} / \mathrm{s}$ at latitudes $30^{\circ}-50^{\circ}$ show that the MDT model performs better that previous models developed by the authors.

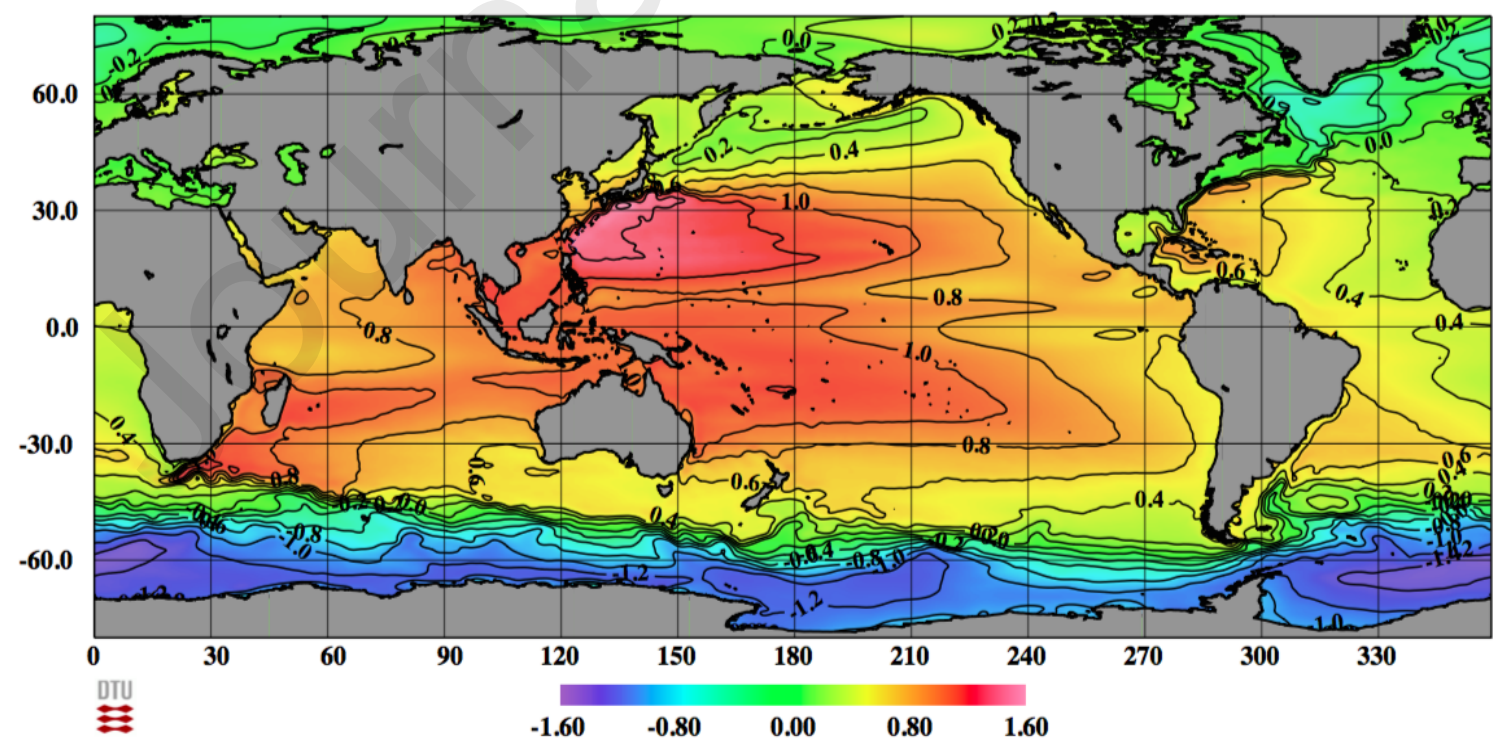

Figure 4: The geodetic mean dynamic topography model DTU17MDT. Units are dynamical meters. 


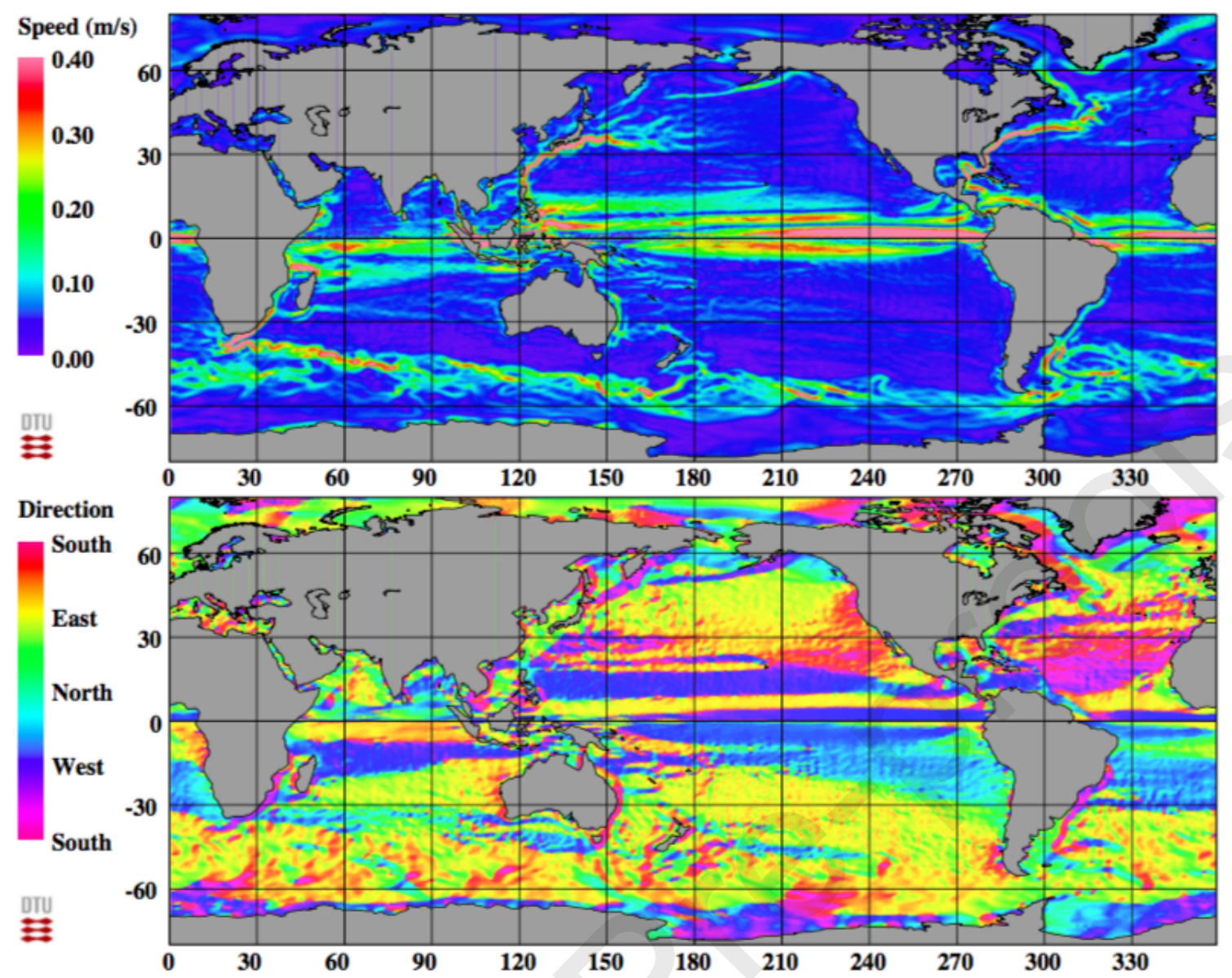

Figure 5: The geostrophic surface currents associated with the geodetic mean dynamic topography model DTU17MDT.

\subsection{The computation of error fields}

The technique applied to derive the MDT model does not allow for rigorous computation of errors. Error terms are needed, however, when the MDT model is assessed or utilised in other ocean modelling approaches. Hence, an alternative method for quantifying the errors has to be applied. In principle, the errors comprise of errors in the MSS, errors in the geoid model (both commission and omission errors), and short scale MDT signals that have been removed by the filtering process. All components are present in the differences between the MSS and the geoid model, i.e., the $\Delta h$ values in eq. (2). It was decided to apply a simple approach to derive the error terms. The errors terms were derived by computing standard deviations associated with the weighted means of the $N \Delta h$ values, i.e.,

$\sigma_{w}^{2}=\frac{\sum_{i=1}^{N} w_{i}\left(\Delta h_{i}-\overline{\Delta h}_{w}\right)^{2}}{\frac{N-1}{N} \sum_{i=1}^{N} w_{i}}$ where $\overline{\Delta h}_{w}=\frac{\sum_{i=1}^{N} w_{i} \Delta h_{i}}{\sum_{i=1}^{N} w_{i}}$

And $w_{i}$ is the weight of the $i$ 'th value coming from the filter. The $N$ values are located within certain radius from the point of interest. The weighted mean heights $\overline{\Delta h}_{w}$ enter the MDT model. Correlated 
errors in the MSS and in the geoid model at scales larger than the filter width have not been included. The estimated error field is shown in Fig. 6. The estimated errors range from a few centimetres to a few decimetres. They exceed $20 \mathrm{~cm}$ in areas of the major ocean currents.

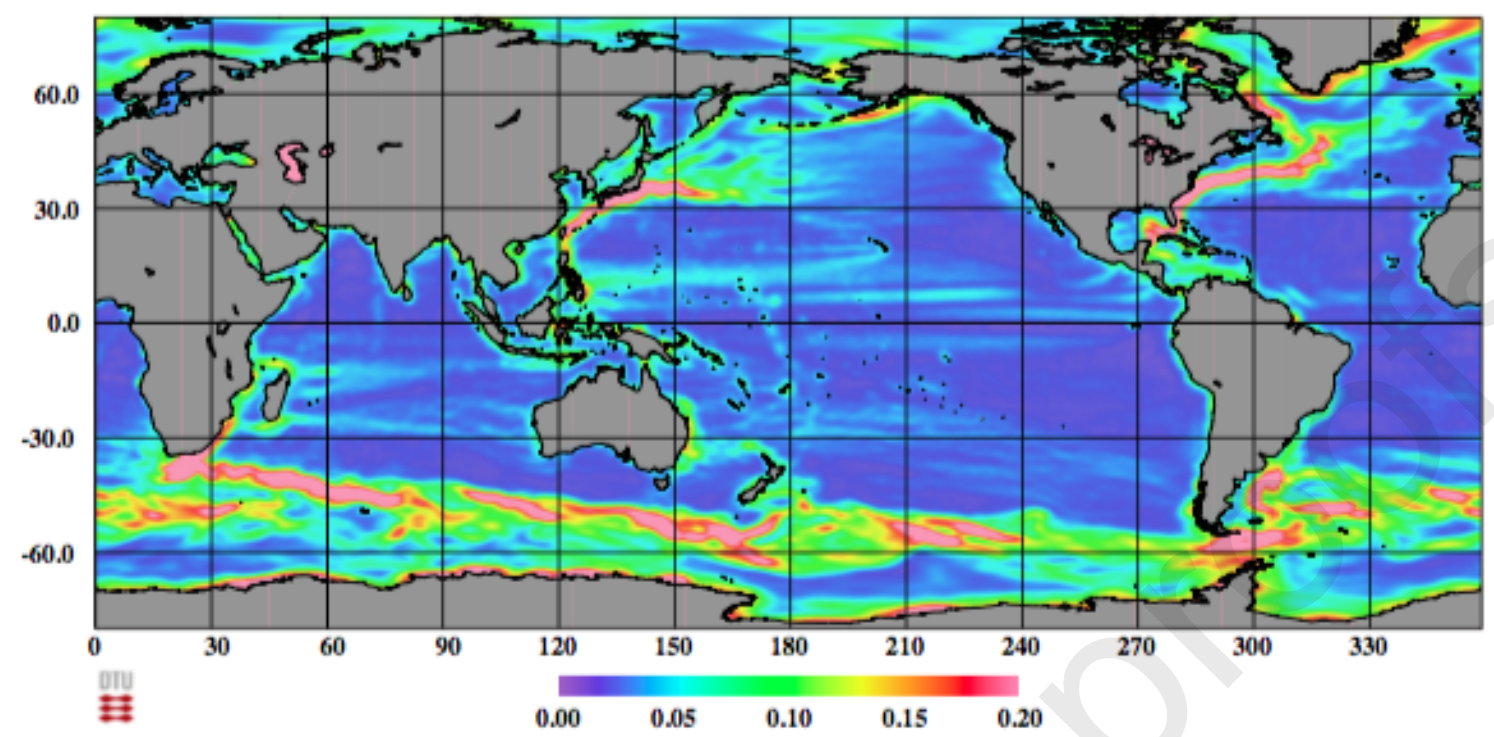

Figure 6: The errors associated with the geodetic mean dynamic topography model. Units are dynamical meters.

\section{Combining the geodetic MDT with drifter velocities}

The geodetic MDTs can be improved if regional signal and noise characteristics are assessed and accounted for. To facilitate an adaptive integration of the data sources, in which the regional characteristics of both the signal and the noise are considered, the error fields described in Section 3 were integrated in the computations. This error field describes the quality of the geodetic MDT. In addition to the error field associated with the MDT, error associated with the mean drifter velocities needs to be considered. There are many error sources contributing to the error of a mean drifter velocity depending on the number of observations and the processing technique of the drifter trajectories, including removal of the wind-driven flows and calculation of the geostrophic current anomalies from satellite altimetry. In this analysis, the errors were quantified empirically using a simple approach. The errors were expressed by using the relation $0.25 / \operatorname{sqrt}(n)[\mathrm{m} / \mathrm{s}]$ where $n$ is the number of 6-hourly drifter data points in the cells in which the mean value is calculated. If $n=25$ an error of $5 \mathrm{~cm} / \mathrm{s}$ is obtained which agrees well with the statistics presented in Fig. 1. In most areas with a good coverage of drifters about 20-40 6-hourly drifter data points are found (see Fig.s A1 and A2).

MDT values in the nodes of a regular grid having a $1 / 4^{\circ}$ by $1 / 4^{\circ}$ spacing were estimated using Eq. (6) augmented to include the geodetic MDT and its errors as a-priori information. The result of this adaptive integration, the DTU17cMDT model, is shown in Fig. 7. The associated geostrophic currents are shown in Fig. 8. The errors of the MDT are shown in Fig. 9. 


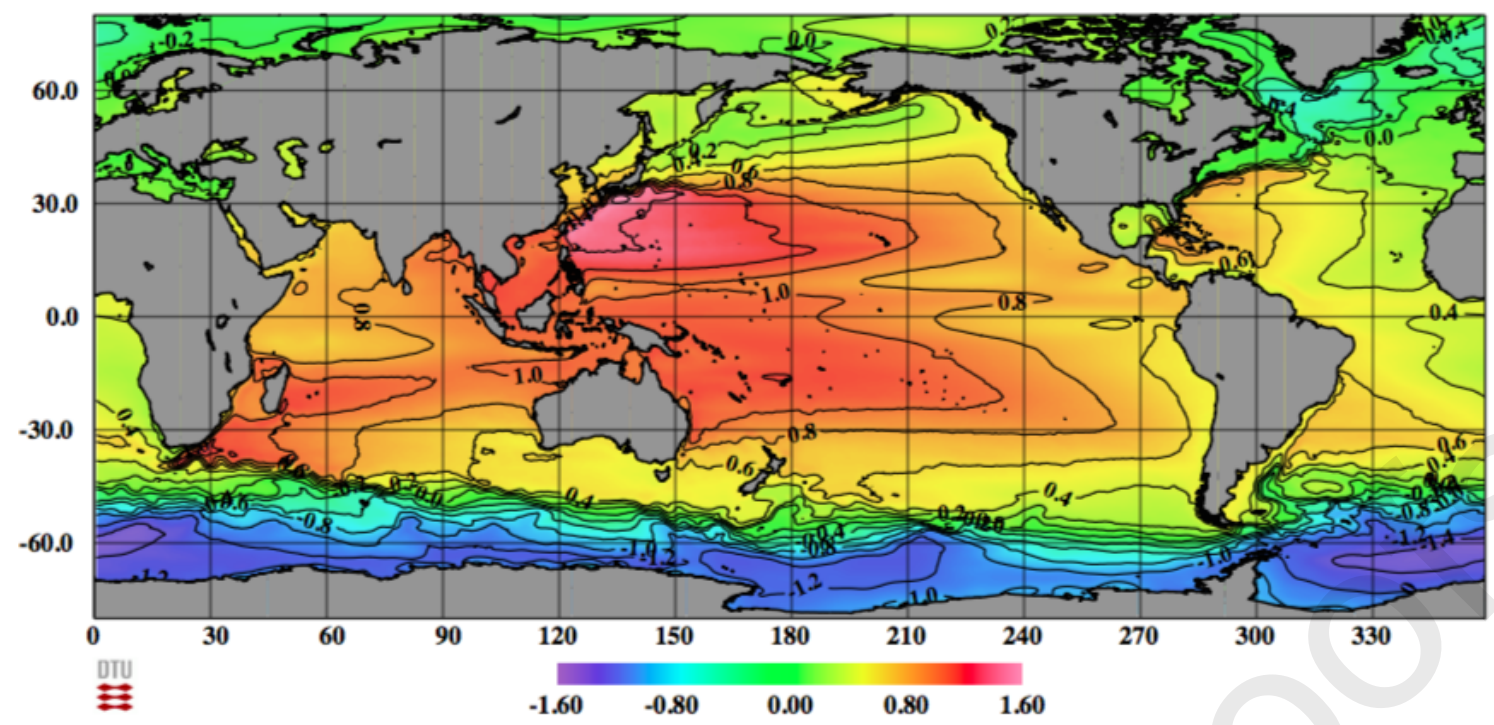

Figure 7. The combination mean dynamic topography model DTU17cMDT. Units are dynamical meters.

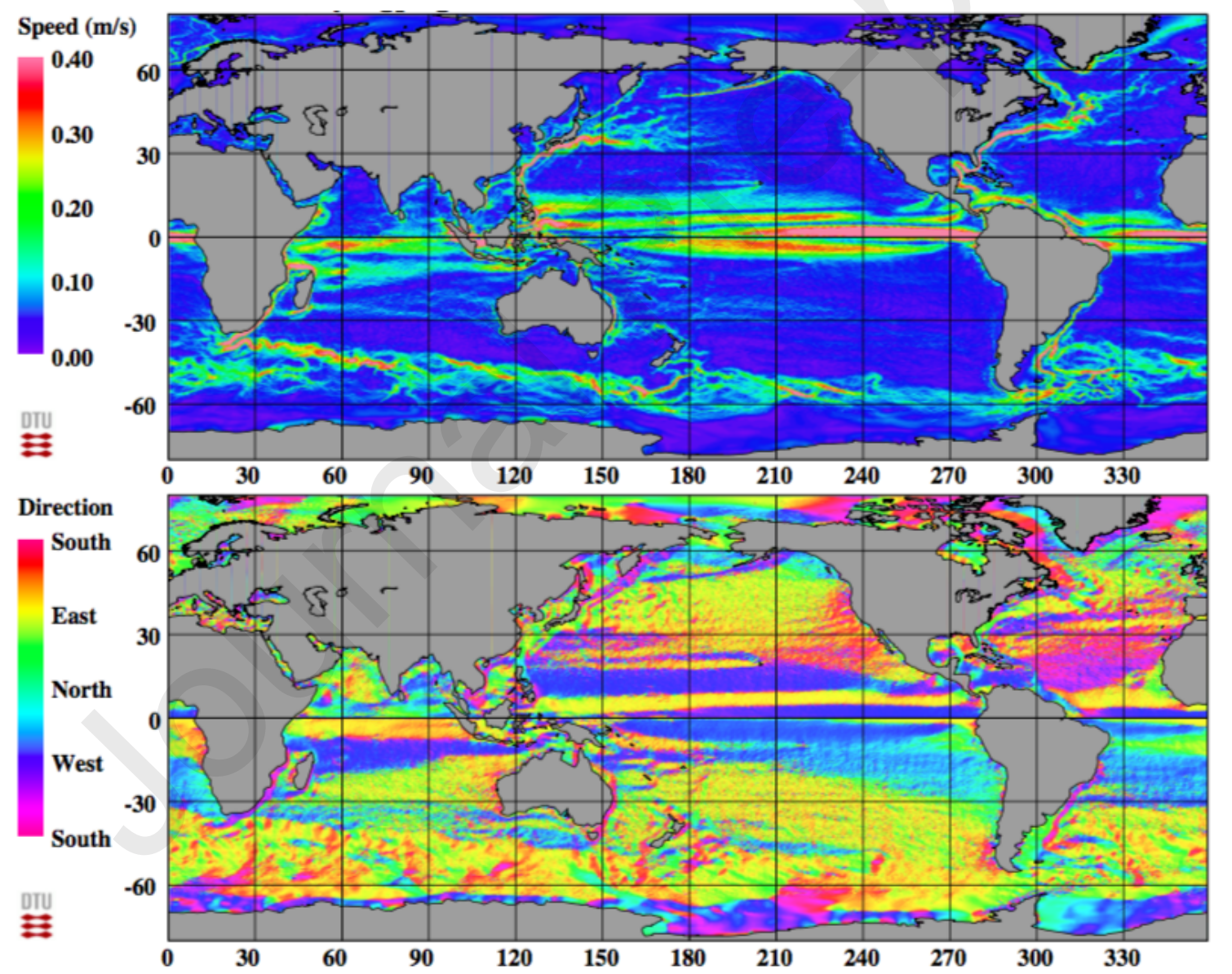

Figure 8. The geostrophic surface currents associated with the combination mean dynamic topography model. 


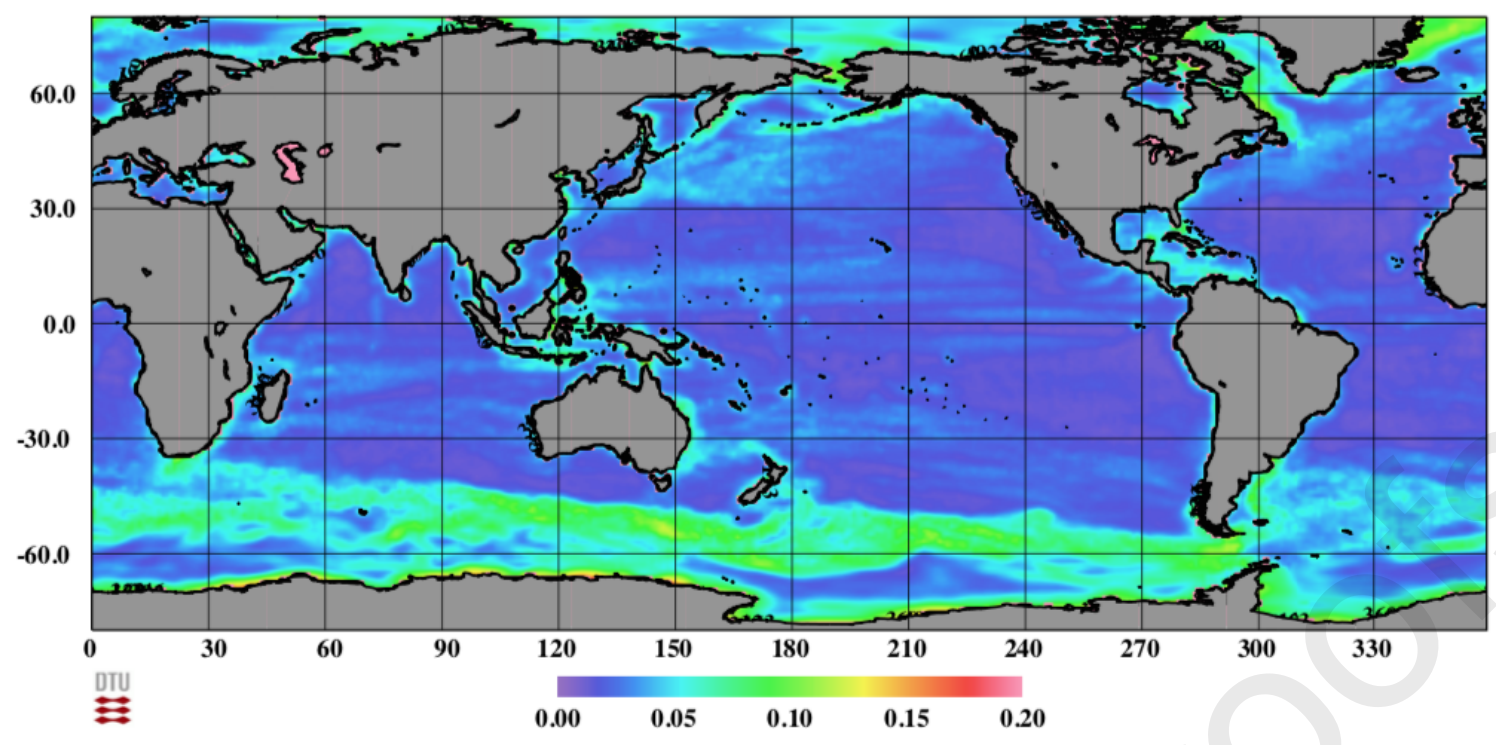

Figure 9: The errors of the combination mean dynamic topography model, DTU17cMDT. Units are dynamical meters.

The effects of integrating the drifter information and, subsequently, to use the error fields in an adaptive integration are clearly demonstrated in the Gulf Stream area. In Fig. 10 two MDT models are shown in the western North Atlantic. Though the two models mostly display the same features, there are visible differences in important details. The spacing between the contour lines off the Florida coast is larger in the map of the geodetic MDT than the other. Also, the geodetic MDT does not recover the MDT changes towards the coast very well. For the combination MDT the contour lines off the Florida coast are much tighter, hereby improving the reproduction of the MDT changes towards the Florida coast.
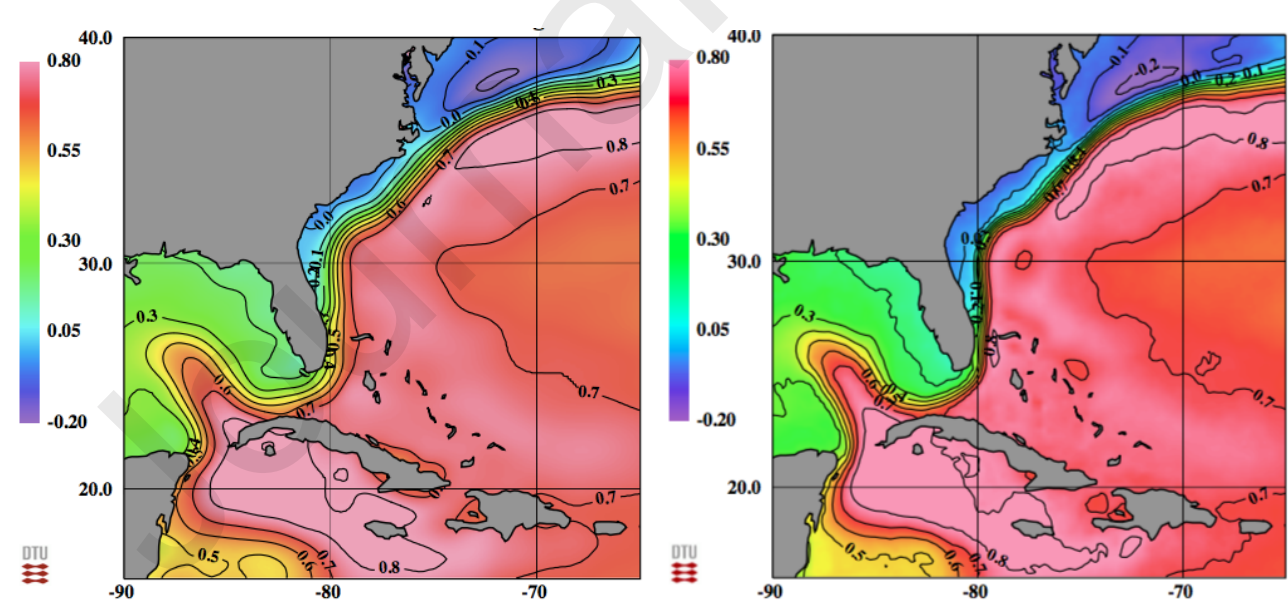

Figure 10. Geodetic MDT (left) and combination MDT (right) in the Gulf Stream area. Units are dynamical meters.

The differences are even better displayed when geostrophic surface current speed in the Gulf Stream area is compared (shown in Fig. 11). Again, the two models generally display the same features. However, the geodetic MDT does not reproduce the geostrophic speed off of the coast 
very well. The combination MDT performs much better; off of the Florida coast the current speed increases from about $0.5 \mathrm{~m} / \mathrm{s}$ to more than $1.0 \mathrm{~m} / \mathrm{s}$.
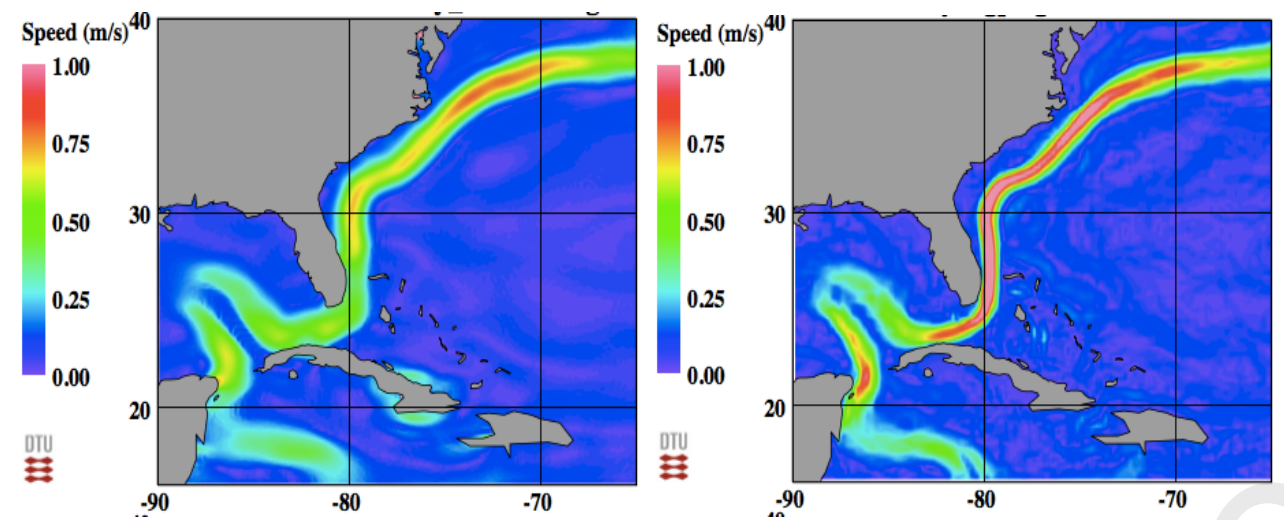

Figure 11. Geostrophic current speed associated with the geodetic MDT (left) and the combination MDT (right) in the Gulf Stream area.

Although, the combination MDT reproduces the Gulf Stream better and succeeds in utilising the smaller scale information contained in the drifter data, more analyses are needed to assess the qualities and differences of the two MDT models. We need to evaluate the models in the areas of weaker currents to see how the drifter information impacts the solutions, both in the areas where drifter data are dense and the areas where drifters are sparse. Based on such analyses the assessment and quantification of the errors of the mean drifter velocities should be revised.

\section{Conclusions}

A new geodetic MDT model DTU17MDT has been computed using the optimal geoid model derived in the OGMOC project. To facilitate an adaptive integration of the additional data sources (drifters), in which the regional characteristics of both the signal and the noise are considered, an error field was derived using an empirical approach. Then a new MDT model was derived by integrating the geodetic MDT and the drifter mean velocities in the computations. The resulting combination model DTU17cMDT reveals more details of the geostrophic surface currents, in particular, the strong western boundary currents are further enhanced when the two sources of information are merged.

Both MDT models presented in this paper are of research quality and more analyses are needed to improve the models. Issues related to the error assessment of both the geodetic MDT (combining geoid and MSS errors) and the mean drifter velocities need to be studied further to improve the estimation of the combination model. Issues along the coasts and linkage between MDT and local geodetic height systems as described by Andersen et al. (2018) need to be considered as well. New MSS and geoid models becoming available will further improve the estimation of the MDT models.

\section{Acknowledgements}

The authors thank Dr. Luca Centurioni, who provided us with the quality-controlled drifter data, interpolated onto 6-hourly intervals, and Dr. Jan Hafner, who helped to interpolate various products on to drifter locations and times. The OGMOC geoid model was provided by Thomas Gruber and Thomas Fecher from the Technical University of Munich. The study was supported by the 
European Space Agency through the Optimal Geoid for Modelling Ocean Circulation (OGMOC) project through CCN9 to the contract no. 18308/04/NL/MM "GOCE High Level Processing Facility (HPF)" led by the Technical University of Munich; NM through a sub-contract with the Technical University of Denmark. NM and PK were partly supported by the US National Aeronautics and Space Administration NASA through grant NNX17AH43G.

\section{APPENDIX. Processing of drifter data}

Drifter data from the period 1992-2015 has been collected and processed. Both drifter data from drogued and un-drogued buoys have been used. As part of the processing the wind-driven flow was modelled using the Ekman formulation and wind data from NCEP. Furthermore, the meso-scale contribution to the geostrophic flow was removed using the AVISO current anomaly product. Finally, the two data sets were merged into mean velocities.

The drifter data are associated with two sets of buoys: The drogued and the undrogued buoys. When launched the buoys are equipped with an anchor floating about $15 \mathrm{~m}$ down in the water column, i.e. the drogue. Hence, the buoy is moving as the ocean at that depth. As the buoy gets older the wire holding the anchor breaks. Now the buoy is no longer attached to the ocean column and will drift according to the winds.

Most of the data are acquired during the altimetry area (1990-). The geographic density of the drogued drifters is shown in Fig. A1. The geographic density of the un-drogued drifters is shown in Fig. A2.

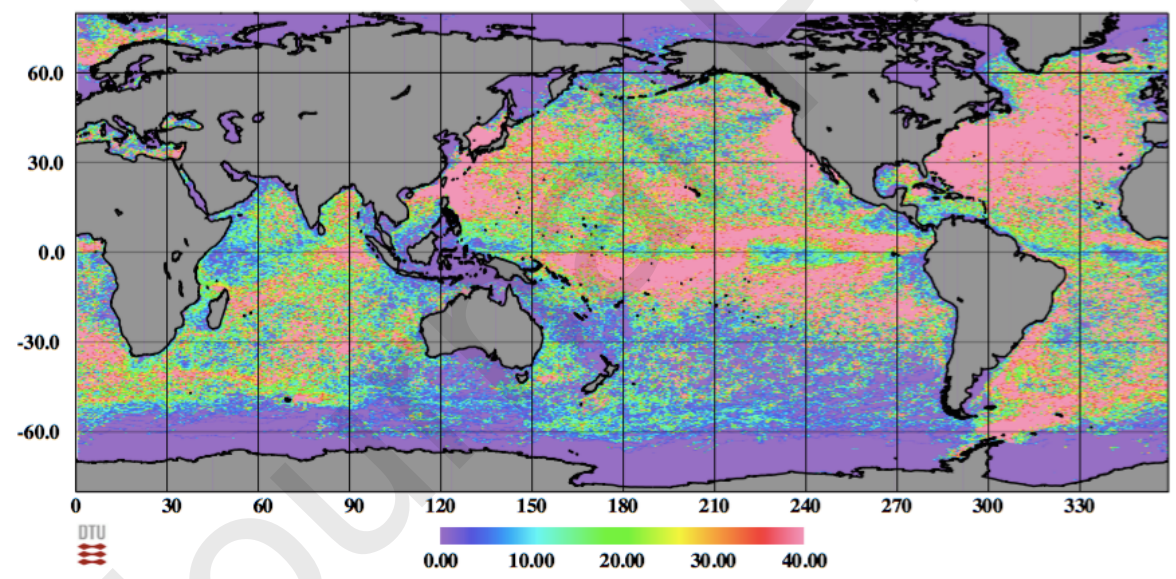

Figure A1. The density of the drogued drifter data from the period 1992-2015 is shown geographically as number of observations in $1 / 4^{\circ}$ by $1 / 4^{\circ}$ cells. 


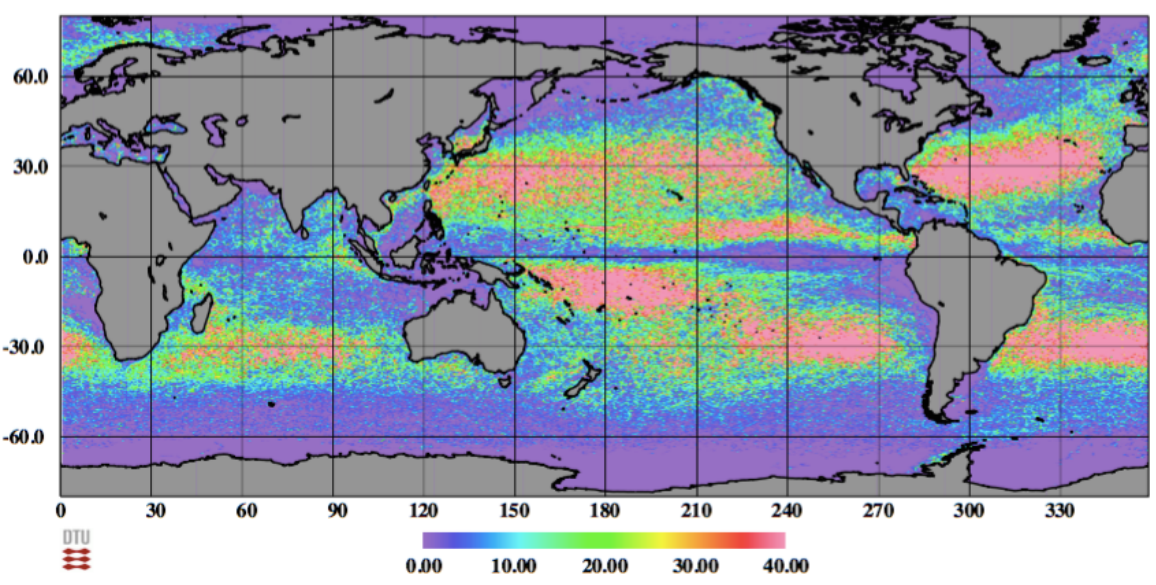

Figure A2. The density of the un-drogued drifter data is shown geographically, as in Fig. A1.

The distributions of the data in time are shown in Fig. A3 for drogued and for un-drogued buoy data respectively. The distributions show that the number of data is well distributed over the 20 years period 1993-2012. The number of the un-drougued data, however, increases over time. The total number of drifter data is $27,254,751 ; 13,599,886$ drogued and $13,654,865$ undrogued drifter data.

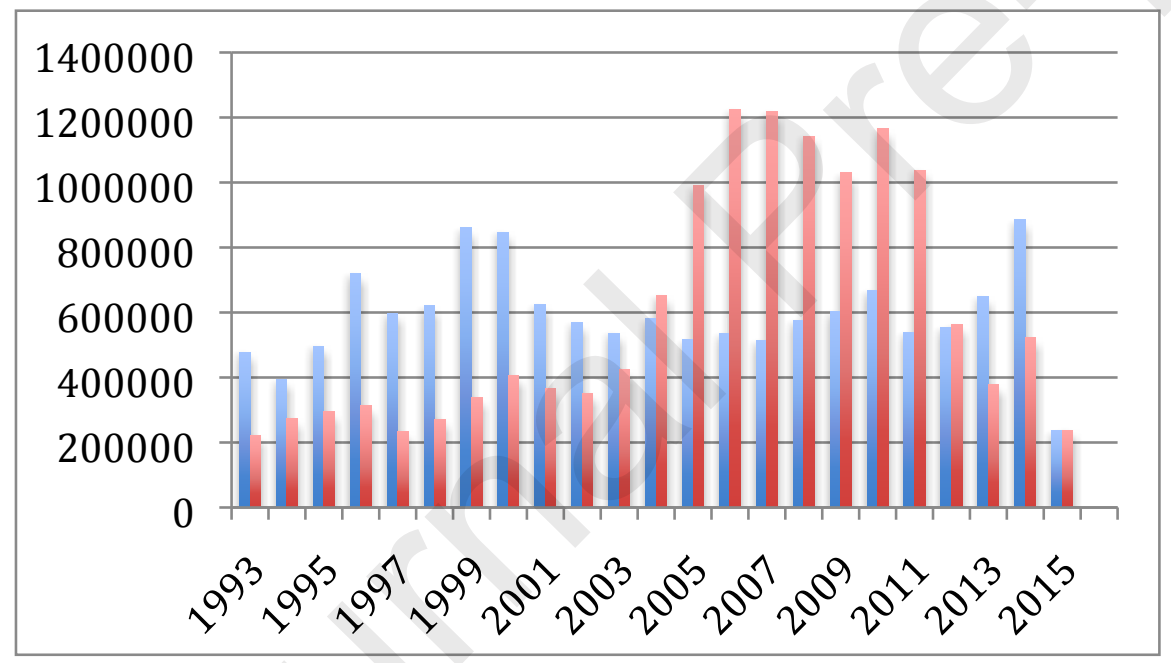

Figure A3. The distribution of the data in time is shown for drogued (blue) and for un-drogued (red) buoy data respectively.

The processing of the raw drifter data has been carried out by others (Maximenko et al., 2009). We need to perform the correction for the wind-driven flows, i.e. the Ekman drift and for the undrogued buoy data an additional wind-driven drift component. The buoy velocity may be described as

$v=v_{G}+v_{E}+v_{W}=\bar{v}_{G}+\Delta v_{G}+v_{E}+v_{W}$

where $v_{G}$ is the geostrophic component which is split into a mean term $\bar{v}_{G}$ and a residual time varying term $\Delta v_{G}$, and $v_{E}$ is the Ekman component. $v_{W}$ is the additional wind-driven drift component which is applied to the undrougued drifter data only. 
In practice the wind-driven Ekman component was computed empirically using the approximation $v_{E}=v_{a}+v_{b}($ Ekman, 1905):

$$
\begin{aligned}
& v_{a}=a \frac{0.0127}{\sqrt{\sin |\phi|}} w \\
& v_{b}=b \frac{-0.0127}{ \pm \sqrt{\sin |\phi|}} \hat{w}
\end{aligned}
$$

where $v_{a}$ and $v_{b}$ are the flow velocity components parallel and perpendicular to the wind vector $w . \phi$ is the latitude. The $+/-$ in the $v_{b}$ component shifts from the Northern hemisphere $(+)$ to the Southern hemisphere (-). Both velocity components are considered and modelled empirically by finding the coefficients $a$ and $b$ by linear regression. Though the approximation should be fairly valid at latitudes larger than $10^{\circ}$ it was decided to carry out the estimation of a and $b$ in $2^{\circ}$ by $5^{\circ}$ cells to adapt to local wind and flow characteristics. However, to avoid local effects to affect the in the computation of $v_{a}$ and $v_{b}$ the coefficients were zonally averaged and fitted by a smooth latitude dependent function.

The wind information given for each drifter velocity in the files is originally obtained from NCEP. The computation of the coefficients, $a$ and $b$, was carried out using the drogued drifter data from where the mean currents calculated from the geodetic MDT have been subtracted. The mean values of the residual currents (relative to the mean currents) as well as the mean values of the winds were removed in each $2^{\circ}$ by $5^{\circ}$ cell. This method was applied to avoid any short scale mean currents to affect the computation and cause the strong fluctuations.

The results of the regressions performed in the $2^{\circ}$ by $5^{\circ}$ cells were averaged zonally (see Fig. A4). Subsequently the coefficients were converted into amplitudes and phases, expressed by $\sqrt{a^{2}+b^{2}}$ and $\tan ^{-1}(a / b)$ respectively (also shown in Fig. A4). Those quantities where represented by simple expressions empirically determined. The average amplitude is 0.39 . The phases are fitted by the following function: $60^{\circ}+15^{\circ} \cdot \cos \left(\phi / 17^{9}\right)-60.0 /\left(|\phi|+1^{\circ}\right)$ (Note that the latitude $\phi$ is expressed in degrees).

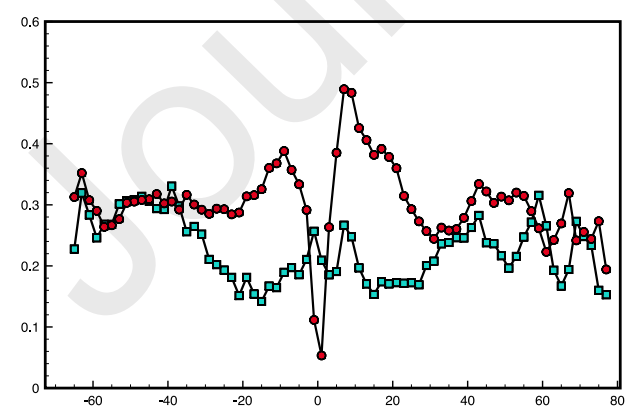



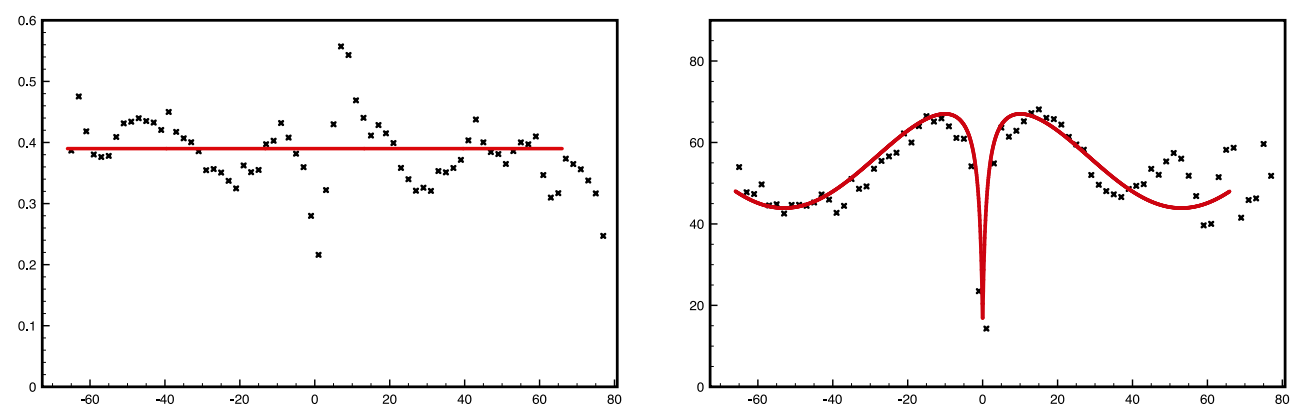

Figure A4. The zonally averaged coefficients, a (blue) and b (red), for the drogued drifters are shown in the upper plot. The average amplitudes (lower left) and the phases (lower right) with the empirically fitted functions. The coefficients and the amplitudes are unit-less; the phases in degrees.

The undrogued buoys are expected to behave differently and react more to the direct wind and wave forcing. Hence, an additional correction is needed to quantify these effects of the missing drogue. In this case, the velocities associated with the undrogued buoys have been corrected for the Ekman drift using the empirically determined expressions described above. Then a second similar procedure estimating a new set of $a$ and $b$ coefficients was carried out. As seen below, and as expected, the main effect is seen in the flow parallel to the wind. This component is about twice the magnitude of the Ekman drift. For the flow perpendicular to the wind, only a small effect is seen. The coefficients were fitted empirically as: $a=\left(\phi / 100^{\circ}\right)^{2}-\phi / 400^{\circ}+0.17$ and $b=\left(\phi / 180^{\circ}\right)^{2}$. The results are shown in Fig. A5.

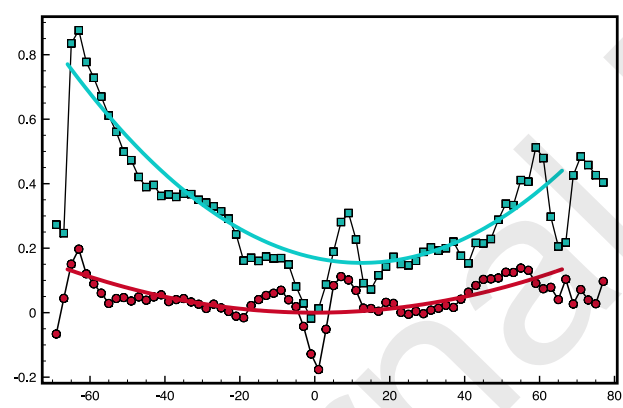

Figure A5. The zonally averaged coefficients, a (blue) and b (red), for the undrogued drifters with the empirically fitted functions added. The coefficients are unit-less.

In addition to the removal of the wind-driven flows the time varying part of the geostrophic flow $\left(\Delta v_{G}\right.$ in eq.A1) needs to be removed in order to reference the velocities to the same 20-years time interval as was used for the mean sea surface, subsequently the geodetic MDT. This is important because the drifters may not recover the full variability in the surface currents at all times during the 20 years averaging period at all locations. This was done by applying the AVISO geostrophic current anomaly product that has been derived using sea level anomalies from satellite altimetry and referenced to the same 20 years time interval. Finally, subsequent to the removal of the wind-driven flows and the geostrophic current anomalies, the drifter velocities were averaged in $1 / 4^{\circ}$ by $1 / 4^{\circ}$ cells. The computed mean currents are shown in Fig. A6. 


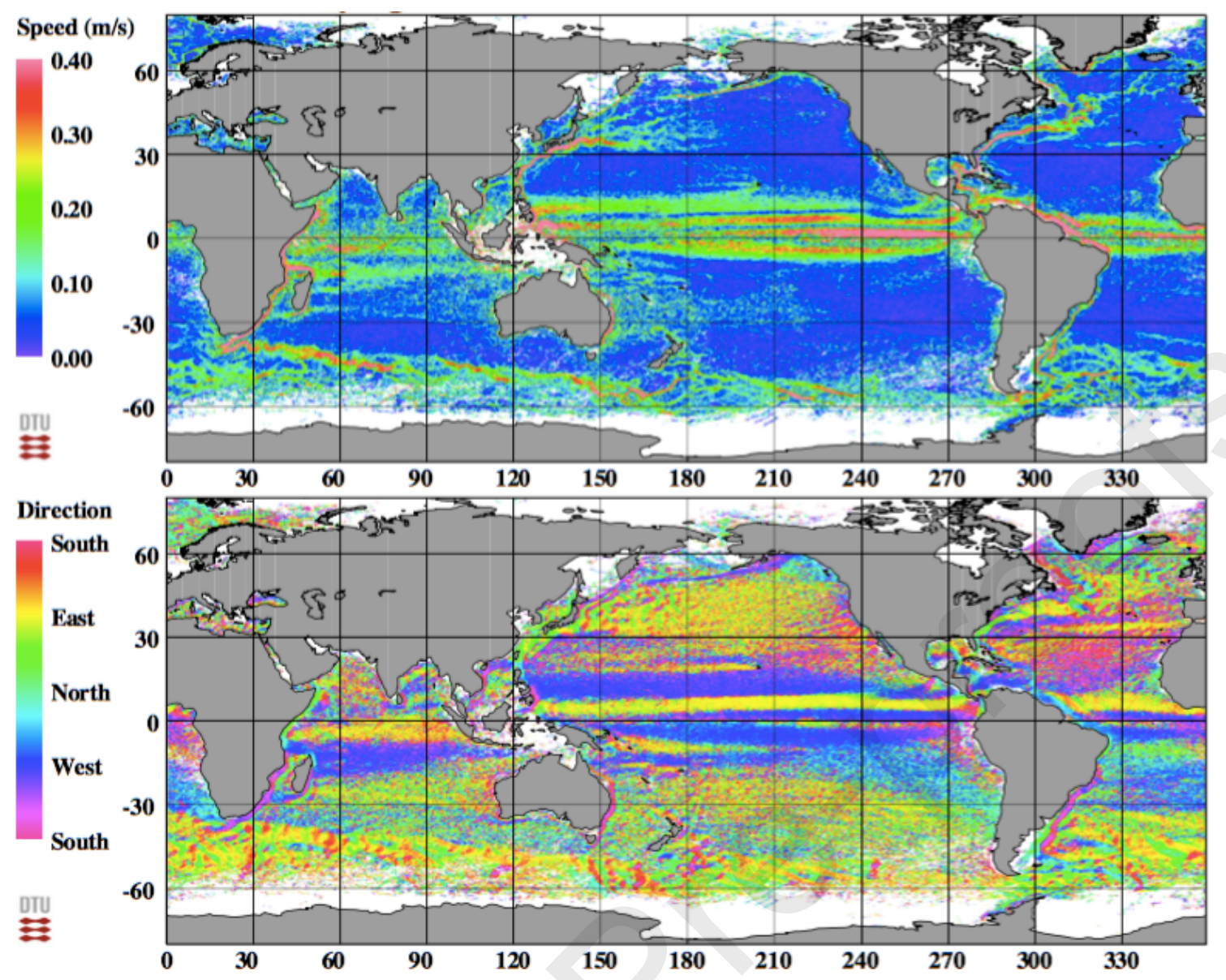

Figure A6. Geostrophic mean surface currents from drifters shown as speed (upper plot) and flow direction (lower plot).

\section{References}

Andersen, O.B., Knudsen, P., and Stenseng, L., 2015. The DTU13 MSS (Mean Sea Surface) and MDT (Mean Dynamic Topography) from 20 Years of Satellite Altimetry. International Association of Geodesy Symposia. Springer, p. 1-10. Doi: 10.1007/1345_2015_182

Andersen, O. B., Knudsen, P., Kenyon, S., Factor, J. K., Holmes, S., 2017. Global gravity field from recent satellites (DTU15) - Arctic improvements. First Break ), vol: 35, issue: 12, pages: 37-40, (ISSN: 0263-5046). http://dx.doi.org/10.3997/1365-2397.2017022

Andersen, O. B., Nielsen, K., Knudsen, P., Hughes, C. W., Bingham, R., Fenoglio-Marc, L., Gravelle, M., Kern, M., Poloo, S. P., 2018. Improving the Coastal Mean Dynamic Topography by Geodetic Combination of Tide Gauge and Satellite Altimetry. Marine Geodesy, vol: 41, issue: 6, pages: 517-545. https://doi.org/10.1080/01490419.2018.1530320

Benveniste, J., Knudsen, P., and the GUTS Team, 2007. The GOCE User Toolbox In: Proceedings of the 3rd International GOCE User Workshop, 6-8 November 2006, Frascati, Italy (ESA SP -627), pages: 265-268 / Edited by Karen Fletcher. - Noordwijk: European Space Agency.

Bingham, R. J., Knudsen, P., Andersen, O., \& Pail, R., 2010. An initial estimate of the North Atlantic steady-state geostrophic circulation from GOCE. Geophysical Research Letters, 38(1), L01606, doi:10.1029/2010GL045633 
Bonjean, F., and Lagerloef, G.S.E., 2002. Diagnostic Model and Analysis of the Surface Currents in the Tropical Pacific Ocean. J. Phys. Ocean., Vol. 32, 2938-2954, https://doi.org/10.1175/1520-0485(2002)032<2938:DMAAOT>2.0.CO;2

Ekman, V. W., 1905. On the influence of the earth's rotation on ocean-currents. Ark. Mat., Astron. Fys., 2, pages: 1-53.

Fecher, T., Pail, R., Gruber, T., GOCO, Consortium, 2017. GOCO05c: A New Combined Gravity Field Model Based on Full Normal Equations and Regionally Varying Weighting; Surveys in Geophysics, Vol. 38, Issue 3, pages: 571-590, Springer. Doi: 10.1007/s10712-016-9406-y

Förste, C., Bruinsma, S., Shako, R., Marty, J-C, Flechtner, F., Abrikosov, O., Dahle, C., Lemoine, J.-M., Neumayer, K.H., Biancale, R., Barthelmes, F., König, R., Balmino, G., 2011. EIGEN-6 - A new combined global gravity field model including GOCE data from the collaboration of GFZ-Potsdam and GRGS-Toulouse; Geophysical Research Abstracts, Vol. 13, EGU2011-3242-2, EGU General Assembly.

Haines, K., Johannessen, J. A., Knudsen, P., Lea, D., Rio, M. -H., Bertino, L., Davidson, F., Hernandez, F., 2011. An ocean modelling and assimilation guide to using GOCE geoid products. Ocean Science, Vol: 7, issue: 1, pages: 151-164. https://doi.org/10.5194/os-7-1512011

Knudsen, P.; Andersen, O.; Honecker, J.; Maximenko, N., 2015.: Assessing GOCE Gravity Models using Altimetry and In-situ Ocean Current Observation; Geophysical Research Abstracts, Vol. 17, EGU2015-4101, EGU General Assembly.

Knudsen, P., Bingham, R., Andersen, O., Rio, M.H., 2011. Enhanced Mean Dynamic Topography and Ocean Circulation Estimation using GOCE Preliminary Models, J. of Geodesy, vol: 85, issue: 11, pages: 861-879. Doi 10.1007/s00190-011-0485-8.

Lagerloef, G.S.E., Mitchum, G.T., Lukas, R.B., and Niiler, P.P., 1999. Tropical Pacific near-surface currents estimated from altimeter, wind, and drifter data, J. Geophys. Res., 104, C10, $23313-$ 23326.

Maximenko, N., Niiler, P., Rio, M.-H., Melnichenko, O., Centurioni, L., Chambers, D., Zlotnicki, V., and Galperin, B., 2009. Mean dynamic topography of the ocean derived from satellite and drifting buoy data using three different techniques. J. Atmos. Oceanic Tech., 26 (9., 1910-1919.

Maximenko, N.A., Lumpkin, R., and Centurioni, L., 2013. Ocean Surface Circulation G. Siedler, S.M. Griffies, J. Gould, and J.A. Church, Eds.), Ocean Circulation and Climate, International Geophysics Series, Volume 103, Academic Press, pages: 283-304.

Niiler, P., 2001. The world ocean surface circulation. In: Siedler, G., Church, J., Gould, J. (Eds.), Ocean Circulation and Climate. International Geophysics Series, vol. 77. Academic Press, pp. 193-204.

Niiler, P.P., 2003. A brief history of drifter technology. In: Autonomous and Lagrangian Platforms and Sensors Workshop. Scripps Institution of Oceanography, La Jolla, CA.

Niiler, P.P., Maximenko, N.A., McWilliams, J.C., 2003. Dynamically balanced absolute sea level of the global ocean derived from nearsurface velocity observations. Geophys. Res. Lett. 30, 2164. http://dx.doi.org/10.1029/2003GL018628.

Rio, M.-H., and Hernandez, F., 2004. A mean dynamic topography computed over the world ocean from altimetry, in situ measurements, and a geoid model. J. Geophys. Res., 109, C12032. Doi:10.1029/ 2003JC002226. 
Rio, M. H., Guinehut, S., and Larnicol, G., 2011. New CNES/CLS09 global mean dynamic topography computed from the combination of GRACE data, altimetry, and in situ measurements, J. Geophys. Res., 116, C07018. Doi:10.1029/2010JC006505

Tikhonov, A. N., 1943. "Об устойчивости обратных задач" [On the stability of inverse problems]. Doklady Akademii Nauk SSSR. 39 (5): 195-198. 


\section{Declaration of interests}

$\bigotimes$ The authors declare that they have no known competing financial interests or personal relationships that could have appeared to influence the work reported in this paper.

$\square$ The authors declare the following financial interests/personal relationships which may be considered as potential competing interests: 